\title{
ПРОЕКТ СОЗДАНИЯ ЭТИМОЛОГИЧЕСКОГО СЛОВАРЯ МОКША-МОРДОВСКИХ ГОВОРОВ САМАРСКОЙ ЛУКИ
}

\section{PROJECT TO CREATE AN ETYMOLOGICAL DICTIONARY OF MOKSHA-MORDOVIAN DIALECTS OF SAMARA LUKA}

N. Belenov

Summary: The article presents the project «Etymological dictionary of Moksha-Mordovian dialects of Samara Luka». The characteristics of the Moksha-Mordovian dialects of Samara Luka and their differences from the identified Moksha-Mordovian dialects are considered. The necessity of creating a dictionary for vocabulary data dialects, discusses the history of the Mordovian lexicography and place develop vocabulary in a series of similar works. It describes the structure of the dictionary as a whole, the principles of its compilation, and provides examples of dictionary entries.

Keywords: etymological dictionary, Mordovian languages, MokshaMordovian dialects, Samarskaya Luka.

\author{
Беленов Николай Валерьевич \\ К.n.н., дочент, Самарский государственный \\ социально-педагогический университет \\ belenov82@gmail.com
}

Аннотация: В статье представлен проект «Этимологического словаря мокша-мордовских говоров Самарской Луки». Рассматриваются характеристики мокша-мордовских говоров Самарской Луки, их отличия от выявленных мокша-мордовских диалектов. Обосновывается необходимость создания словаря на материалах лексики данных говоров, рассматривается история мордовской лексикографии и место разрабатываемого словаря в ряду подобных работ. Описывается структура словаря в целом, принципы его составления, приводятся примеры словарных статей.

Ключевые слова: этимологический словарь, мордовские языки, мокша-мордовские говоры, Самарская Лука.

мордовские говоры Самарской Луки при этом значительно отличаются и друг от друга, что осознаётся их носителями. Эти отличия лежат, главным образом, в области лексики. В процессе полевых исследований нами было выделено три мокша-мордовских говора на Самарской Луке: торновский (бытует в среде мокша-мордовского населения села Торновое Волжского района Самарской области), шелехметский (бытует в среде мокша-мордовского населения села Шелехметь Волжского района Самарской области) и бахиловский (бытует в среде мокшамордовского населения села Бахилово Ставропольского района Самарской области, ранее распространялся также на посёлок Бахилова Поляна Ставропольского района Самарской области). Лексический состав каждого из выделенных говоров отражает этноязыковую историю его носителей, содержит ряд мордовских лексических архаизмов, которые имеют особенность сохраняться в периферийных и изолированных диалектных ареалах, а также по ряду иных аспектов представляет несомненный интерес для лингвистов, историков и этнологов. Вместе с тем, работа по сбору и классификации лексического материала мокша-мордовских говоров Самарской Луки не терпит отлагательств, поскольку в настоящее время происходит активное вытеснение данных говоров из бытового общения в силу ряда демографических процессов, среди которых: естественная убыль носителей мокша-мордовских говоров, замещение коренного населения Самарской Луки приезжим и т.д. 
Для мордовских языков в настоящее время имеется лишь один этимологический словарь, авторства В.И. Вершинина - «Этимологический словарь мордовских (эрзянского и мокшанского) языков», четыре тома которого вышли в Марий Эл в период с 2004 по 2009 годы [2].

Вместе с тем, история мордовской лексикографии начинается в 1692 году, когда в работе о России голландского учёного и политического деятеля Н. Витсена «Северная и Восточная Тартария» в Амстердаме был опубликован список мордовских слов, включающий 323 лексемы, который представлял собой мордовскоголландский словарь [3]. По мнению А.П. Феоктистова, большинство лексем списка Н. Витсена принадлежит западному диалекту мокша-мордовского языка [4. С. 11].

B конце XVIII столетия нижегородский епископ Дамаскин (в миру Д. Семёнов-Руднев) по личному распоряжению Екатерины II составляет пятиязычный словарь, озаглавленный им «Словарь языков разных народов, в Нижегородской епархии обитающих, имянно: россиян, татар, чювашей, мордвы и черемис». Словарь был закончен за 7 месяцев на 1000 листах в двух томах и передан в Нижегородскую семинарскую библиотеку в 1785 году [5. С. 33]. Работу над этим ценнейшим источником затрудняет тот факт, что он рукописный. Мордовскую часть словаря Дамаскина с научными комментариями издал А.П. Феоктистов [4].

Значительный интерес для исследователей мокшанского языка и мордовской диалектологии представляют работы преподавателя Тамбовской духовной семинарии Павла Петровича Орнатова. Его перу принадлежит первая грамматика мокшанского языка, составленная для диалекта тамбовских мокшан [6]. К сожалению, второй труд П.П. Орнатова - русско-мокшанский словарь, составленный им с помощью носителей мокшанского языка, «Словарь русско-мордовский наречия мордвымокши» - так и остаётся неизданным. Пока работа исследователя рассматривалась в различных инстанциях, он умер - словарь же Синод был готов издать лишь после устранения автором ряда недочётов (по мнению проверяющих). Издание русско-мокшанского и мокшанскорусского словарей, подготовленных П.П. Орнатовым, с современным научным комментарием, является одной из актуальнейших задач мордовской диалектологии.

Информативной и, во многом, уникальной работой по мокша-мордовскому языку является труд И.Г. Черапкина «Мокша-мордовско - русский словарь с грамматическим справочником», содержащий мокша-мордовский лексический материал, неизвестный по другим подобным словарям [7].
Особого внимания заслуживают работы Хейкки Паасонена, лично собиравшего словарные материалы среди мокшан и эрзян в конце XIX и в начале XX веков, результатом чего явился фундаментальный труд «Mordwinisches Wörterbuch», по настоящее время остающийся незаменимым источником по мордовской диалектологии [8].

Из приведённого обзора явствует, что проектируемый этимологический словарь изолированной группы мокша-мордовских говоров, с одной стороны, является первым в своём роде, с другой - при его составлении можно опираться на авторитетные работы по мордовской лексикографии, большинство из которых, не являясь этимологическими словарями по определению, во многом являются таковыми по содержанию.

В соответствии с заявленными целями создания словаря (ввод в научный оборот лексических материалов мокша-мордовских говоров Самарской Луки для форсирования дальнейших этноязыковых и этноисторических исследований данной группы мордвы), предлагается следующая структура словарной статьи:

- в заглавие статьи выносится соответствие рассматриваемой лексеме в литературно-письменном мокша-мордовском языке;

- форма и значения лексемы в мокша-мордовских говорах Самарской Луки;

- соответствия лексеме в мордовских говорах ближайшего окружения (в Самарском Поволжье и на смежных территориях Ульяновского и Саратовского Поволжья, Оренбуржья, Татарстана);

- форма и значение лексемы в литературно-письменных мордовских языках и их диалектах;

- соответствия в других финно-угорских языках;

- соответствия в других уральских, индоевропейских и алтайских языках (если имеются);

- вероятная праформа, этимология, обсуждения, дискуссии.

Сокращения языков в создаваемом словаре приняты стандартные, в соответствии с ГОСТ 7.75-97. Если в словаре приводятся примеры из других этимологических словарей, сокращения даются в соответствии с теми, которые приняты в первоисточниках: например, у В.И. Вершинина «общепермский» - «общеп.», у В.И. Лыткина и Е.С. Гуляева - «общеперм.».

Мордовские лексемы приводятся на кириллице во всех случаях, за исключением их извлечения из источников, написанных на латинице (это относится, например, к материалам, собранным X. Паасоненом и представленным в Mordwinische Wörterbuch) - в этих случаях сохраняется авторская графика. 
В примерах словарных статей, приведённых ниже, пока недостаточно представлен второй структурный уровень - сравнение с лексемами соседних с Самарской Лукой мордовских говоров и иных мордовских говоров Самарского Поволжья, так как работа по сбору данного материала нами ещё ведётся. Заглавие статьи выделяется жирным шрифтом, словарные примеры выделены курсивом, ударение - жирным шрифтом соответствующей литеры.

\section{Примеры словарных статей:}

\section{Bene}

В мокша-мордовских говорах Самарской Луки: виле т. - деревня, село; виле ш. - деревня, село; виля б. - деревня, село.

В говорах мордвы Самарского края: веле э., Алёшкино Похвистневского р-на Самарской обл. - деревня; село; веле э., Малый Толкай Похвистневского р-на Самарской обл. - деревня; веле э., Старосемейкино Красноярского р-на Самарской обл. - село.

В мордовских литературно-письменных языках и диалектах: веле м. - деревня, село, жители села, избушка на отшибе, пчелиный рой, улей, пасека; веле э. - деревня, село, рой (вообще); виле м., Алькино Ковылкинского р-на респ. Мордовия - деревня; село; веля м., Барашево Сасовского р-на Рязанской обл. - деревня, село [8. Т. 3. С. 258]; велезем м., Зубова Поляна Зубово-Полянского р-на респ. Мордовия - селище, место бывшего поселения [9. C. 310].

В других финно-угорских языках: falu венг. - деревня, село; valve саам. - свора, стая; -выла л.мар. - суффикс множественности [2. Т. 2. С. 53]; вел г.мар. - страна, сторона; вель коми-зыр. - довольно много [10. С. 45].

Нельзя исключать заимствование из тюркских языков: авыл тат. - село, деревня; ауыл баш. - село, деревня; авыл ног. - село, деревня.

При этом, обращает на себя внимание семантическая параллель мордовских урбанистических терминов: веле и кура со значением «рой, скопление». Происхождение термина автохтонно в мордовских языках, по меньшей мере - до середины XVII века: так, у Н. Витсена отмечена лексема Jomluvele со значением «деревня» [3. С. 433]. Также заслуживает внимания глагол велемомс м. - ожить, прийти в себя, воскреснуть, восстановить силы [9. С. 311].

\section{Курка}

В мокша-мордовских говорах Самарской Луки: кужо т. - полоса необработанной земли, окраина огорода; кужо ш. - окраина обработанной земли, окраина поселения, годоним Кужо ш. - устаревшее название улицы Горная; кужу б. - окраина обработанной земли, окраина поселения.

В говорах мордвы Самарского края: kиžä э. Старое Вечканово Исаклинского р-на Самарской обл. - угол поля; kužo э., Степная Шентала Кошкинского р-на Самарской обл. - переулок; кужо м., Старая Бинарадка Красноярского р-на Самарской обл.

В мордовских литературно-письменных языках и диалектах: кужа м. - поляна, прогалина; кужо э. - поляна, улица, круг; место для хоровода; kužе м., Мордовский Юрткуль - пастбище, лесной луг, просека; kuža м., Темниково Темниковского р-на респ. Мордовии - проталина [8. T. 2. C. 139].

В других финно-угорских языках: кушын удм. - поляна, открытое место в лесу; кӧжа ком. перм. - гравий; куза ком. яз. - галечник, мелкое место на реке с галечным дном; хіร̌ манс., хант. - песок; kushker саам. - песчаная отмель [11. С. 99]; kiidzin лив. - тина, мох, растущий на дне водоёмов; kiz вепс. - мох, растущий на дне водоёмов [12. С. 44].

В.И. Вершинин сближает с перм. *kušз - голый, а также мар. кокша - лысый, плешивый [2. Т. 2. С. 90], В.И. Лыткин также возводит к *kuš общеперм. - голый, обнажённый и сопоставляет с keto фин. - луговина, поляна [10. С. 61], что сомнительно.

Учитывая многочисленные балто-мордовские параллели, в том числе, в географической лексике, В.Н. Топоров приводит топонимическую прусскую основу kus c неясной трактовкой [13. Т. 3. С. 33]. Также неясно, можно ли привлекать др-русск. *гоща - подсека, пожога, сведённый лес [14. С. 59].

Д.В. Цыганкин рассматривает лексему «кужа/кужо» как элемент лексической архаики в мордовских языках со значением «поляна; открытое место» [15. С. 167], что подтверждается её полным отсутствием в ряде эрзя-мордовских говоров Самарского Поволжья: большетолкайском, малотолкайском, красноключёвском, большеёгинском, ерзовском, захаркинском, а также в эрзя-мордовских говорах Бугурусланского района Оренбургской области.

Исходя из многочисленных параллелей в финноугорских языках с соответствующей семантикой, ряд исследователей считает возможным принятие гипотезы о финно-угорской праформе, реконструируемой в виде *kүс̌з - песок, песчаное место [10. С. 101].

\section{Кура}

В мокша-мордовских говорах Самарской Луки: кура 
6. - озеро, пруд, в составе топонимов Веркурай кереметь и Алкурай кереметь; т., ш. - отсутствует, обозначение озера, пруда: эрькхе, буа т., эрьке, пандалу ш.

В говорах мордвы Самарского края: куринка э., Ст. Вечканово Исаклинского р-на Самарской обл. - улица, в составе топонимов Содоу-куринка, Шоколадная куринка; куринка э., Захаркино Сергиевского р-на Самарской обл. - улица, в составе топонима Од-куринка; куринка э., М. Толкай Похвистневского р-на Самарской обл. - дальняя часть улицы; куре м., Ст. Бинарадка Красноярского р-на Самарской обл. (старобинарадский материал представляет особую ценность, ввиду того, что имеются архивные сведения о переселении части бахиловской мордвы в деревню Бинарадка в XVIII веке) - небольшое село, в составе топонимов: Вере-куре; Кунчка-куре.

В мордовских литературно-письменных языках и диалектах: kura э., Ст. Вечканово Исаклинского р-на Самарской обл., kura м., Юрткули (совр. Базарный Юрткуль) Старомайнского р-на Ульяновской обл.- кустарник; место, где растёт много ягод и грибов; порядок; участок улицы; куринка э., Нуштайкино Бугурусланского р-на Оренбургской обл. - другая сторона улицы (относительно говорящего); -kuro э., Б. и М. Маресево Чамзинского р-на респ. Мордовия - аффикс общности; -kuren м., Корсаевка Белинского р-на Пенз. обл. - аффикс общности [8. Т. 2. С. 100]; кура м., Салазгорь Торбеевского р-на респ. Мордовия - улица; сообщество соседей, проживающих на одной улице. Д.В. Цыганкин реконструирует * кера древнеморд. - поселение [16. С. 56].

В других финно-угорских языках: kurи фин. - борозда; kuristik эст. - овраг, ущелье; карем г.мар. - овраг, ложбинка; корем, кором л.мар. - обрыв, впадина; кыр коми зыр. - обрыв.

Обращают на себя внимание параллели в вост-слав. и тюрк. языках: Курья рус. (Пермский край) - залив реки, расположенный на месте старого русла, застоявшаяся вода, где река заходит в сторону, топкое болото на месте бывшего русла реки [17. С. 36]; курья рус. (Курская область) - заводь, а также в гидронимии: Кур, Курица [18. С. 15]; курень рус. (Пермский край) - место вырубки леса [17. С. 36]; курень укр., также в донских говорах - жилой дом; курень укр. - войсковое подразделение в казачьем украинском войске; kuren польск. - землянка, лачуга [19. C. 123], а также в тюркских: карья тат. - деревня; kuran чаг. - скопление людей, отряд воинов, племя; кӱршӗ чув. низ. - сосед [20. С. 60].

По-видимому, необходимо различать группы гидронимических и урбонимических терминов, хотя общность происхождения исключать нельзя. Для гидронимических терминов обращает на себя внимание распространённая в ряде этноязыковых сред бинарная связь лексем «река - овраг». Также на топонимическом материале А. Алквист [21] и П. Рахконен [22] вычленяют детерминант kar, на основании которого П. Рахконен реконструирует лексему * kur со значением озеро [21. С. 14; 22. С. 8]. Для урбонимов характерно полное семантическое соответствие в восточнославянских и мордовских языках, при сохранении идентичной основы, что едва ли случайно. Учитывая ряд балтских соответствий (kors лат. - просека [23. С. 318; 24. С. 55]; kur прусск. - неэтимологизируемая топонимическая основа [13. Т.4. С. 194]), можно предполагать для всего данного кластера некий общий источник заимствования, неидентифицируемый на данном этапе исследования. Не исключено, что изначально термин имел общее собирательное значение, в свете чего обращает на себя внимание куравны коми-зыр. - собирать, собрать; куран коми-зыр. - грабли; на основании чего В.И. Лыткин реконструирует *kur/kёr общеперм. - сгрести, собрать вместе; добавляя, что эти звукоподражательные слова могли возникнуть в различных языковых ветвях независимо друг от друга [10. С. 112], при этом интересно отметить у Махмуда Кашгарского: kӥrё д.-тюрк. - сгребать, грести [25. С. 328].

Гурт удм. - деревня, село; курт хант. - посёлок, повидимому, привлекать нельзя, поскольку они восходят к иному первоисточнику с общим значением «очаг»; между тем, кар удм. - город, городище, укреплённое место, возможно, восходит к той же урбонимической основе [26. C. 111].

Значимость создаваемого «Этимологического словаря мокша-мордовских говоров Самарской Луки» для дальнейших исследований по всестороннему изучению самаролукской мордвы определяется следующими обстоятельствами:

- создаваемый словарь является первым лингвистическим исследованием такого рода по мокшамордовским говорам Самарской Луки;

- этническая история мордвы Самарской Луки до сих пор остаётся предметом дискуссий, выдвигаемые при этом гипотезы не могут быть подтверждены или опровергнуты без дополнительных лингвистических доказательств, базу для которых может предоставить разрабатываемый словарь;

- введение лексических материалов мокша-мордовских говоров Самарской Луки в научный оборот имеет значение для мордовского языкознания в целом, поскольку данные говоры содержат лексические и семантические архаизмы, утраченные в других мордовских диалектах. 


\section{Принятые сокрашения}

т. - торновский говор мокша-мордовского языка

ш. - шелехметский говор мокша-мордовского языка

б. - бахиловский говор мокша-мордовского языка

м. - мокша-мордовский литературно-письменный язык, а также указание языковой принадлежности го- вора того или иного села к мокшанскому языку э. - эрзя-мордовский литературно-письменный язык, а также указание языковой принадлежности говора того или иного села к эрзянскому языку л.мар. - лугово-восточный марийский язык г.мар. - горномарийский язык

\section{ЛИТЕРАТУРА}

1. Феоктистов А.П. Диалекты мордовских языков // Mordwinisches Worterbuch. Helsinki, 1990. - Bd. I. - S. LX - LXXXV.

2. Вершинин В.И. Этимологический словарь мордовских (эрзянского и мокшанского) языков. Т. 1-4. - Йошкар-Ола: СТРИНГ, 2004 - 2009.

3. Witsen N. Noord en oost Tartarye. - Amsterdam, 1692.

4. Феоктистов А.П. Русско-мордовский словарь. Из истории отечественной лексикографии. - М.: Наука, 1971. - 371 с.

5. Матичак Ш. Истоки мордовской письменности // Финно-угорский мир. - 2015. - №1. - С. 24-35.

6. Орнатов П.П. Мордовская грамматика, составленная на наречии мордвы мокши. - М.: Синодальная типография, 1838. - 120 с.

7. Черапкин И.Г. Мокша-мордовско-русский словарь с грамматическим справочником. - Саранск: МордГИЗ, 1933. - 193 с.

8. Paasonen X. Mordwinische Wörterbuch. T. 1-3. - Helsinki, 1990-1995.

9. Серебренников Б.А., Феоктистов А.П., Поляков О.Е. Мокшень-рузонь валкс. - М.: Дигора, 1998. - 920 с.

10. Лыткин В.И., Гуляев Е.С. Краткий этимологический словарь коми языка. - М.: Наука, 1970. - 386 с.

11. Керт Г.М. Саамская топонимная лексика. - Петрозаводск: Карельский научный центр РАН, 2009. - 179 с.

12. Муллонен И.И. Очерки вепсской топонимии. - СПб.: Наука, 1994. - 157 с

13. Топоров В.Н. Прусский язык. Словарь. - М.: Наука, 1975 - 1990. Т. 1-5.

14. Шилов А.Л. Заметки по исторической топонимике Русского Севера. - М.: АСТ, 1999. - 100 с.

15. Цыганкин Д.В. Мордовская архаическая лексика в топонимии Мордовской АССР // Ономастика Поволжья. - Саранск, 1976. Вып. 4. - С. $167-171$.

16. Имайкина М.Д., Цыганкин Д.В. От Суры. . . до Мокши: названия рек и озёр республики Мордовия: этимологические разыскания. - Саранск: Изд-во Морд. ун-та, 2010. - 108 с.

17. Полякова Е.Н. От «араины» до «яра». Русская народная географическая терминология. - Пермь: Пермское книжное изд-во, 1988. - 180 с.

18. Щавелёв С.П. Первооткрыватели курских древностей: Очерки истории археологического изучения южнорусского края. - Курск: ERA, 1997. - 139 с.

19. Vasmer M. Russisches etymologisches Wörterbuch. Heidelberg: Universitatsverlag Carl Winter. 1958. $2890 \mathrm{s.}$

20. Ашмарин Н.И. Заметки по чувашской диалектологии // Материалы по чувашской диалектологии. - Чебоксары: Чувашское гос. изд-во, 1960. - 195 с.

21. Альквист А. Меряне, не меряне // Вопросы языкознания. 2000. №2. - С. 15-35.

22. Рахконен П. Границы распространения меряно-муромских и древнемордовских гидронимов в верховьях Волги и бассейне Оки // Вопросы ономастики. 2012. №1. - C. 5-42.

23. Никонов В.А. Краткий топонимический словарь - М.: Наука, 1966. - 509 с.

24. Эндзелин Я.М. Славяно-балтийские этюды. - Харьков: М. Зильберберг и сыновья, 1911. - 208 с.

25. Древнетюркский словарь / Наделяев В.М., Насилов Д.М., Тенишев Э.Р., Щербак А.М. - Л.: Наука, 1969. - 677 с.

26. Беленов Н.В. Мокша-мордовская топонимия Самарской Луки. - Самара: Порто-принт, 2018. - 200 с.

(с) Беленов Николай Валерьевич (belenov82@gmail.com).

Журнал «Современная наука: актуальные проблемы теории и практики» 